\title{
Expresión cartográfica y atributos urbanísticos de Valdivia y Nueva Imperial (sur de Chile): un análisis comparado
}

\author{
Cartographic expression and urbanism of Valdivia and Nueva Imperial (southern Chile): a comparative analysis
}

\section{Constanza Chamorro* y Simón Urbina**}

Recibido: 23 de marzo de 2018

Aceptado: 11 de octubre de 2018

\section{Resumen}

En este trabajo exponemos el resultado del análisis planimétrico basado en la sistematización de información cartográfica e histórica de dos ciudades del sur de Chile: Valdivia (39 $\left.48^{\prime} 00^{\prime \prime} \mathrm{S} 73^{\circ} 14^{\prime} 00^{\prime \prime} \mathrm{O}\right)$ y Nueva Imperial ( $\left.38^{\circ} 44^{\prime} 00^{\prime \prime} \mathrm{S} 72^{\circ} 57^{\prime} 00^{\prime \prime} \mathrm{O}\right)$. A partir de dos conjuntos de planos históricos se logró determinar elementos urbanísticos representativos de cada ciudad, sus fases de crecimiento urbano y patrones de división predial, las cuales son valoradas de forma individual y combinada, dentro de procesos históricos y territoriales más amplios.

El estudio distingue sustanciales diferencias cronológicas y en el proceso político que les dio origen, sin embargo, ambas manifiestan claras similitudes en el emplazamiento, escala y atributos propios del damero hispanoamericano que, como veremos, siguió vigente durante la ocupación chilena de la Araucanía a fines del siglo XIX. La proyección del ejercicio analítico presentado busca su aplicabilidad en el estudio de las ciudades del Sur Austral de Chile, reponiendo la necesidad de trabajo interdisciplinario sobre colecciones de planos y cartografías de ciudades alojados en diversos archivos regionales, nacionales y extranjeros.

Palabras clave: Análisis planimétrico, ciudades del siglo XIX, ciudades del sur Chile, urbanismo hispanoamericano.

\begin{abstract}
This paper presents a planimetric analysis based on the systematization of documents, cartography and historical information of two southern cities of Chile: Valdivia $\left(39^{\circ} 48^{\prime} 00^{\prime \prime} \mathrm{S} 73^{\circ} 14^{\prime} 00^{\prime \prime} \mathrm{W}\right)$ and Nueva Imperial $\left(38^{\circ} 44^{\prime} 00^{\prime \prime} \mathrm{S} 72^{\circ} 57^{\prime} 00^{\prime \prime} \mathrm{W}\right)$. From two groups of historical cartography, representative urbanistic elements, urban growth phases, and patterns in the property division were determined for each city. The urban history of those cities is valued individually and jointly, in a broader historical and territorial process.

The study distinguishes substantial chronological differences in the political process that originated the two cities. However, both present similarities in its location, scale and the own attributes of the Spanish American checkerboard street plan--active during the Chilean occupation of Araucanía in the late nineteenth century. The projection of the analytical methodology presented seeks its relevance for the study of other cities in southern Chile, valuing the interdisciplinary work on cartographic collections and cartography of cities preserved in diverse local, national and international archives.
\end{abstract}

Keywords: 19th century towns, Hispano-American urbanism, planimetric analysis, southern cities of Chile.

\footnotetext{
* Dirección museológica, Universidad Austral de Chile. Contacto: constanza.chamorro@uach.cl,

** Escuela de Arqueología, Sede Puerto Montt, Universidad Austral de Chile. Contacto: simon.urbina@uach.cl
}

Proyecto FONDECYT 1171735. Transformaciones e interacción en la Plaza Presidio de Valdivia durante el siglo XVIII: asentamientos, redes y circulación de materialidades. IR: Dra. Leonor Adán.

Proyecto DID-ES-2016-01, Universidad Austral de Chile. Ciudades tempranas y cultura material en territorio mapuche: análisis urbanistico y de colecciones museológicas (s. XVI y XVII). IR: Dr. Simón Urbina.

Cómo citar: Chamorro, C. y Urbina, S. (2018). Expresión cartográfica y atributos urbanísticos de Valdivia y Nueva Imperial (sur de Chile): un análisis comparado. Revista de Urbanismo, 39, 1-16. https://doi.org/10.5354/0717-5051.2018.48762 


\section{Introducción}

De acuerdo a las primeras investigaciones regionales, la búsqueda sistemática de planos y cartografías históricas es una labor fundamental para el análisis comparado de los primeros núcleos urbanos americanos (Guarda, 1965; Palm, 1951). Especialmente cuando la orientación de estos estudios es procesual y contextual, vale decir orientada a la comprensión de los procesos sociales en contextos geopolíticos concretos, un registro cartográfico completo y seriado permite comprender integralmente el desarrollo urbano de las primeras ciudades en tanto asentamientos arqueológicos y cuya expresión física puede ser comparada y discutida con las evidencias documentales (Calvo, 2008; Guarda, 1978). Este trabajo apunta a caracterizar el proceso de transformación de las ciudades de Valdivia y Nueva Imperial atendiendo a sus trayectorias particulares diacrónicas y a los contextos en los cuales sus configuraciones responden a procesos culturales y territoriales sincrónicos en el sur de Chile. El objetivo específico de este estudio es explicitar el proceso de análisis y los resultados obtenidos a partir del estudio de esta clase de documentos (planos históricos de ciudades) ubicados en archivos nacionales y extranjeros, así como el tratamiento de dos conjuntos cartográficos ordenados en términos diacrónicos.

El trabajo comparativo que aquí presentamos responde a la pregunta, de índole arqueológica y urbanística, sobre las trayectorias y procesos de establecimiento, transformación y abandono que involucraron las ciudades meridionales chilenas (Figura 1). Esta investigación se enmarca en un contexto mayor de estudio orientado a comprender la expansión urbana de Valdivia en el siglo XVIII, y sus efectos posteriores, desde una perspectiva histórica, material o arqueológica y etnográfica. Por esta razón y debido a que la muestra es inabarcable en un trabajo monográfico de corta extensión, en esta oportunidad nos centraremos en dos casos que ejemplifican este proceso y que permiten una comprensión general de la problemática global referida. La segunda pregunta con la que hemos elaborado este estudio es de índole metodológica y refiere al procedimiento analítico planteado, desde las etapas de búsqueda y transcripción planimétrica, la perspectiva arqueológica e histórica que imponen el tratamiento de las fuentes cartográficas hasta la exploración interpretativa de los resultados, sin pretender con ello arribar a un modelo de interpretación general aplicable a todos los núcleos urbanos del sur de Chile.

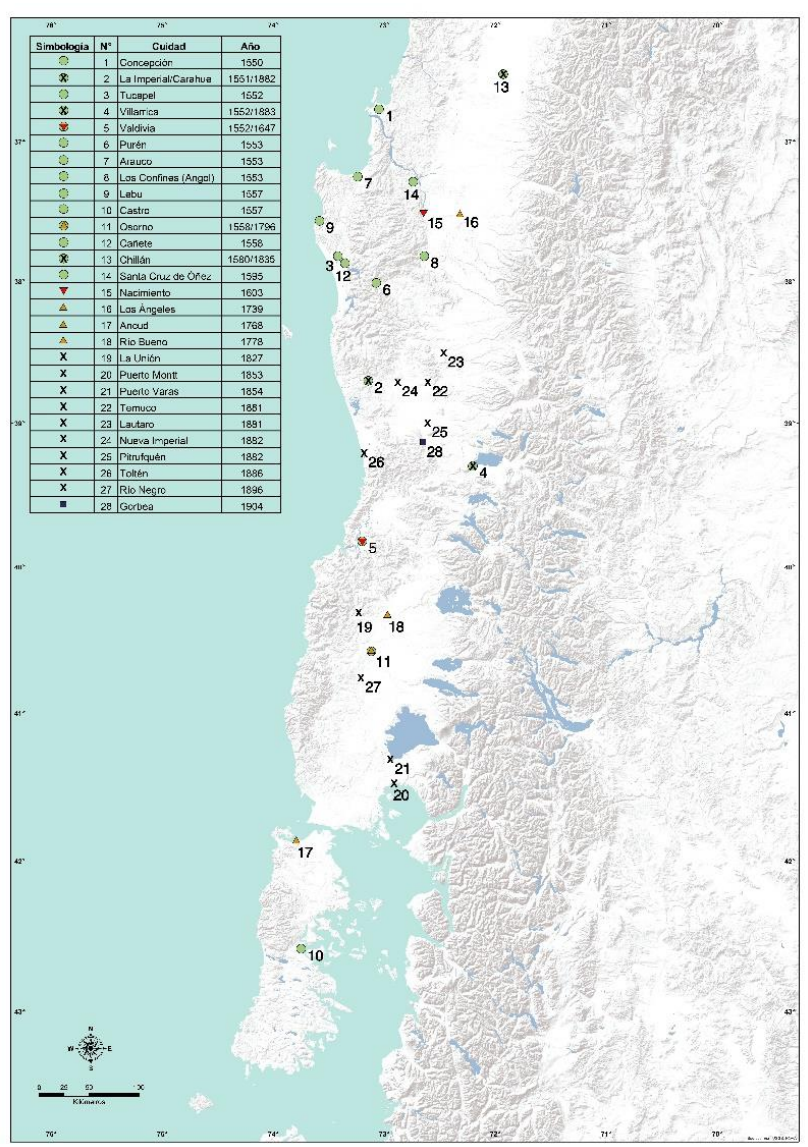

Figura 1. Principales ciudades fundadas en el sur de Chile entre 1550 y 1904.

Fuente: Elaboración propia.

Los casos que hemos seleccionado -Valdivia y Nueva Imperial- representan dos procesos urbanísticos, en principio dicotómicos, dada la diferencia cronológica de su primera fundación -1552 y 1882 respectivamente-, no obstante, hacia fines del siglo XIX y comienzos del XX se pliegan a una historia común dentro de la zona sur austral de Chile en el período Republicano. Siguiendo los planteamientos de Bermann para el desarrollo de la arquitectura andina (1993), nuestra hipótesis de trabajo considera que los cambios geopolíticos ocurridos entre fines del siglo XVIII y XIX, no siempre provocaron cambios inmediatos en el diseño de las viviendas o en la planificación urbana de las ciudades luego del proceso de independencia en el sur de Chile (1820-1826). Esto implica a nivel teórico que las transformaciones, innovaciones o emergencia de nuevas estructuras sociales pueden manifestarse a través de ritmos históricos diferentes a los cambios verificados en la vida material de las sociedades humanas, vale decir, no necesariamente un cambio de régimen político-cultural implica el surgimiento de nuevos modelos de planeamiento urbano en los centros de poder, 
en regiones distantes de ellos o sometidas a proceso de colonización territorial.

Considerando las fuentes analizadas, en el caso de Valdivia, los planos históricos representan conformaciones urbanas y proyectos realizados entre los años 1643 y 1853, comprendiendo la etapa de ocupación holandesa en el siglo XVII, sobre las ruinas del damero del siglo XVI (1552-1599), la refundación de Valdivia (1647) y el período Republicano en los albores de la colonización alemana. En el caso de Nueva Imperial la serie cartográfica corresponde a planos de proyecto y levantamientos planimétricos datados entre 1882 y 1984, vale decir entre su fundación y fines del siglo XX, donde incluso los planos más recientes representan el trazado existente en la actualidad y, al mismo tiempo, proyectan nuevas villas en el sector norte como veremos en los apartados siguientes. Los documentos planimétricos estudiados poseen un valor patrimonial indudable, tanto por las diferentes técnicas de representación, los sistemas de medición y origen de los dibujantes. También condensan información sobre eventos y episodios históricos: fundación, destrucción y refundación y, especialmente, una sobreposición de cambios de menor escala generados por nuevas legislaciones, el régimen de propiedad de la tierra y disposiciones urbanísticas aplicadas sobre ellas por políticas gobiernos locales (municipales) o nacionales.

En términos más amplios, consideramos que el incremento de la investigación histórico-arqueológica en contextos urbanos permitiría una nueva comprensión de ciudades latinoamericanas de origen colonial y republicana, considerando a su vez los antecedentes prehispánicos y la influencia de la arquitectura vernácula en su desarrollo ulterior. Este enfoque consecuentemente aportaría a las ciencias que estudian los fenómenos urbanos en sus variadas dimensiones (el urbanismo, la historia urbana, la geografía humana, etc.), así como la mejor definición de Zonas de Conservación Histórica o de Interés Patrimonial, un escenario de convergencia entre las ciencias sociales y naturales para el estudio de temas simultáneos.

A continuación, se exponen los fundamentos de la investigación y el proceso de análisis planimétrico detallando los pasos metodológicos esenciales que permiten su aplicación futura en otros núcleos urbanos de la macroregión. Se sistematizan los distintos niveles de información y cruce de datos generados a nivel del plano general y de la división predial. Finalmente, discutimos los resultados obtenidos en el marco de los procesos históricos generales documentados en este territorio austral de Chile como las implicancias de la evolución urbana particular de cada ciudad analizada.

\section{Consideraciones sobre el análisis planimétrico- arqueológico}

Junto con las investigaciones académicas, las dinámicas de crecimiento urbano en las ciudades del sur de Chile durante las últimas tres décadas- impulsaron numerosas intervenciones estratigráficas en ciudades chilenas de origen colonial (1552-1820) o republicano (1820-1960), obligando en ciertos casos a extensos y masivos rescates de áreas de ocupación. Debido a lo anterior y al aumento significativo de las colecciones museológicas, los estudios arqueológicos gatillados por hallazgos imprevistos, la restauración de inmuebles históricos, la construcción de obras nuevas en zonas patrimoniales y los análisis sobre ordenamiento territorial, se percibe un activo escenario en el cual la investigación arqueológica actual comienza a abordar problemas y períodos usualmente trabajados por la historia urbana (Barría, 2017; Contreras, 2015; Guarda, 1978; Rosas, Hidalgo, Strabucchi y Bannen, 2015).

Por otra parte, hacia fines del siglo XX, Sanhueza y coautores indicaban que "... los aportes de la arqueología histórica en la comprensión del período histórico han sido escasos, siendo la historiografía (chilena) la disciplina que ha tenido un rol preponderante en este aspecto" (Sanhueza, Henríquez, Prado, Reyes y Núñez, 2004, p. 107). Sin embargo, los primeros estudios arqueológicos enfocados en los períodos tempranos de la colonización hispana se cuentan a partir de la década de 1970 (Ortiz, 1971), un ciclo paralelo y relacionado con el avance de la etnohistoria y la antropología histórica en Chile.

Un lugar destacado en el debate académico actual se relaciona con la profundidad que alcanzan los estudios inter y transdisciplinarios frente a procesos urbanos coloniales y republicanos en Latinoamérica, clarificar las interacciones entre poblaciones durante el período de invasión europea, procesos de colonización, vida fronteriza, conflictos bélicos, procesos de hibridación cultural, auge y decadencia económico-cultural (siglos XVXXI) y como estos se manifiestan en los distintos componentes urbanísticos y en la percepción y memoria que se tiene de ellos.

El desafío teórico-metodológico que imponen el registro histórico-arqueológico de nuestras ciudades actuales reside en plantear una línea de trabajo que describa la compleja constitución de este tipo de asentamientos nucleados y planificados -las ciudades constituyen sitios arqueológicos pluriestratigráficos-, donde se registran asociados y sobrepuestos múltiples evidencias, testigos y niveles de información. 


\section{Desarrollo del análisis planimétrico}

La metodología aplicada fue primariamente desarrollada para sistematizar información documental, planimétrica e histórica disponible para la ciudad de Valdivia, a partir de cuyos resultados se plantea el actual análisis (Guarda, 2009; Urbina, Adán y Chamorro, 2017; Urbina y Chamorro, 2016). Este modelo fue utilizado luego en el estudio del área fundacional de Nueva Imperial, aun cuando esta ciudad no cuenta con estudios arqueológicos o intervenciones publicadas en el perímetro urbano (Munita, Peña-Cortés y Farías, 2013, p. 300-301). En el caso de Valdivia, en trabajos anteriores nos hemos aproximado a este tipo de análisis, comparando las superficies establecidas por los planos coloniales y la distribución y características de las evidencias arqueológicas -muebles e inmuebles- reconocidas en el perímetro urbano de Valdivia (Urbina et al., 2017).

A partir de las obras publicadas y la búsqueda sistemática de planos cartográficos en archivos nacionales y extranjeros, se seleccionaron para digitalizar planos en alta resolución, a excepción del plano Ferro-Carril de Temuco a Carahue, cumpliendo con el criterio de ofrecer representaciones de la totalidad del área urbana, como de sectores o edificios particulares.

La prospección de archivos históricos ha permitido identificar un conjunto de 367 planos históricos de 85 ciudades y fortificaciones entre el siglo XVI y XIX, entre Arica y Ancud. Estos documentos se han recopilado en versiones digitalizadas ya disponibles o solicitadas provenientes de distintos archivos bibliotecas, museos e institutos universitarios de América y Europa. Los planos de ciudades del siglo XVI y XVII conforman una fracción muy reducida de la muestra $(3,3 \%)$, generalmente planimetrías ideales donde la información refiere a la distribución de solares entre vecinos fundadores (por ejemplo, Mendoza y San Juan), mientras que planos tempranos que representan un levantamiento real de las áreas fundacionales son sumamente escasos. Dentro de la macro región de estudio casos excepcionales son las ciudades de Concepción, con 22 planos fechados entre los años 1712 y el año 1896; Valdivia, con 13 planos datados entre 1643 y 1924; Osorno, con 11 planos documentados entre 1796 y 1924; mientras Carahue (ciudad de La Imperial), solo está documentada con 4 planos del tiempo de su refundación a fines del siglo XIX.

Cada plano entrega información urbanística específica, donde se representan con distintos grados de profundidad el paisaje, el emplazamiento y extensión de los asentamientos, la arquitectura y el ordenamiento del espacio edificado. En algunos casos predomina atributos generales del trazado y detalles de las construcciones existentes o bien las proyecciones que se esperan ejecutar en cada caso (planos de proyecto o diseño); también se agregan atributos naturales de importancia como cursos fluviales, relieve y cobertura vegetacional (Adán, Urbina y Alvarado, 2017). Un elemento significativo se encuentra en algunos planos donde se especifica la repartición de terreno dentro de las manzanas o loteos, donde pueden ser analizados los patrones y modalidades de división predial vigentes en cada época y ciudad, como sus transformaciones posteriores.

En este trabajo nos concentramos en los planos que reúnen todos los elementos mencionados, especialmente en aquellos del siglo XIX que se concentran o detallan ciertos elementos edilicios de las Áreas Fundacionales, en detrimento de aquellos que muestran las expansiones periféricas o representan con mayor detalle elementos del paisaje circundante. Los problemas interpretativos generados por ausencia de información pueden ser compensados mediante el trabajo con la serie completa de planos; utilizando información arquitectónica y testimonios históricos presenciales de las épocas estudiadas o mediante el análisis de distintos indicadores (Contreras, 2016; Espinoza y Zumelzu, 2016; Rosas et al., 2015; Zumelzu, Burgos y Navarro, 2016). La comprensión de la secuencia de planos históricos, en este sentido, depende directamente de los antecedentes históricoarqueológicos de cada asentamiento, aunque su ausencia no constituye necesariamente un impedimento para el estudio de la evolución urbana a partir de cada pieza y la serie temporal que integran

Las series de tres planos seleccionados para Valdivia y tres para Nueva Imperial fueron sometidos a un proceso de transcripción lineal, escalamiento o conversión de medidas en desuso (codos holandeses, varas castellanas, toesas) a un sistema métrico decimal, y corrección cardinal mediante el uso de sistema de coordenadas geográficas universales (UTM) disponibles en sistemas de visualización satelital de la superficie terrestre (Google Earth).

La digitalización en alta calidad es fundamental para identificar las escalas gráficas en los planos o los sistemas de anotación indirecta de ella, como ocurre en el plano holandés de Valdivia (1643) donde se utilizan puntos consecutivos equidistantes en la parte superior del plano (Vid infra). La ausencia de escala en planos del período Colonial, como el plano de la Plaza de Valdivia (1763), plantea un problema crucial en el análisis planimétrico, como en el procedimiento de posicionamiento sobre la planta actual. Este dilema puede ser resuelto mediante la identificación de elementos representados en el plano y subsistentes en la planta actual, posibilitando el cálculo de dimensiones y superficies a partir de la sobreposición de las transcripciones lineales y el "amarre" de los planos 
históricos a elementos vigentes en el presente -calles, esquinas de edificios o contornos de manzanas-. Otra alternativa es tomar medidas expresadas en testimonios registrados documentalmente, aunque este paso metodológico debe ser considerado como provisional y sometido a contrastación posterior mediante nueva información planimétrica o evidencias de arquitectura arqueológica.

El posicionamiento de los planos sobre las planimetrías actuales de las áreas urbanas posibilita la delimitación, zonificación y planteamiento de hipótesis sobre el crecimiento de la trama urbana y analizar la evolución particular de manzanas, solares, calles y edificios. También permite contrastar la información urbanística generada por excavaciones en las áreas fundacionales de cada ciudad -entendidas como la superficie ocupada por la primera fundación-, planificar la realización de futuras intervenciones estratigráficas o entregar medidas de protección o rescate para el patrimonio urbano que se halla en el subsuelo e informar preventivamente a los organizamos municipales o ministerios encargados del desarrollo de proyectos de infraestructura y equipamiento (Munita et al., 2013; Romero y Ajata, 2014; Urbina, Adán, Munita y Mera, 2012).

Una vez que la transcripción lineal tiene la corrección cardinal y escalamiento a centímetro, se ha realizado la sobreposición sobre imágenes satelitales actuales y, por último, sobre planos urbanos provistos por las municipalidades de Valdivia y Nueva Imperial en formato AutoCAD. Como resultado de este análisis se pueden obtener superficies exactas y formas del relieve sobre el cual ha sido establecida cada ciudad, la extensión del área fundacional y determinar de este modo las Zonas de Conservación Histórica o posicionar elementos desaparecidos del entorno natural y elementos paisajísticos afectados por el crecimiento urbano.

El análisis permite, por último, apreciar el efecto de las medidas adoptadas por los gobiernos locales en términos de planeamiento o densificación, como sobre el sistema de tenencia de tierra, loteo o división predial dentro de cada manzana edificada. La sobreposición de los planos históricos sobre la planta actual permite de este modo obtener información directa sobre el patrón de asentamiento común entre las ciudades fundadas en un periodo determinado, los elementos divergentes que entre ellas surgieron producto de las coyunturas locales y la aplicación de modelos urbanísticos de distinta naturaleza y origen (local, nacional o foráneo).

\section{Resultados}

El análisis planimétrico nos ha permitido relevar información arquitectónica y urbana de diferente calidad, producto del tipo de registro cartográfico disponible en cada caso. En este plano nos interesa resaltar los patrones de instalación de las dos ciudades analizadas, Valdivia y Nueva Imperial, donde el damero o retícula se ve representada en dos contextos históricos y geográficos. En Valdivia el trazado de la ciudad está determinado a partir de 1552 por limitantes topográficas y soluciones particulares en la fisonomía de las manzanas y centralidad de la plaza mayor (Guarda, 1965); en Nueva Imperial, el damero se despliega desde el año 1882 programáticamente sin aparentes problemas. La comparación planimétrica de Valdivia y Nueva Imperial permite observar elementos característicos del proceso urbanizador, fases de despoblamiento repentinos 0 graduales, producto del asedio y destrucción de algunos núcleos urbanos a fines del siglo XVI.

\section{Valdivia}

Se ha relevado el plano holandés de la ciudad de Valdivia, alojado en la Universidad de Göttingen, Alemania (Figura 2a). El plano fue levantado en 1643 en el marco de la expedición holandesa de aquel año, donde se muestra la ciudad de Valdivia en ruinas producto del abandono posterior al alzamiento general de 1599-1604, y da cuenta del trazado de la ciudad en 1552 sobre un asentamiento indígena preexistente y las modificaciones posteriores al terremoto de 1575.

El documento muestra la traza de manzanas cuadradas y mayormente rectangulares apaisadas de acuerdo a la orientación norte-sur del río. Destaca la gradación cromática para dar cuenta de los distintos parches y tipos de vegetación, así como los cambios en el relieve sobre el cual se disponía la ciudad, su relación con el curso fluvial y otros cursos de agua como los dos desagües de humedales o vertientes ubicadas en el interior de la ciudad. El plano posee una escala gráfica en codos equivalentes a $69 \mathrm{~cm}$, a partir de lo cual pudo efectuarse el escalamiento por sobreposición del plano sobre la trama actual, alcanzando el área urbana una extensión de 53,7 hectáreas.

El segundo plano que hemos analizado corresponde al periodo de refundación de Valdivia y representa La Plaza Real o castillo de Valdivia, según Antonio Birt (1763, Figura 2b). Posterior a la transcripción lineal, se ha escalado en metros la planta y posicionándola cardinalmente de acuerdo a la propuesta de Guarda $(2009$, p. 19) quién ha utilizado en este posicionamiento distintos testimonios contenidos en la documentación histórica del siglo XVII y XVIII. La Plaza Real presenta elementos urbanísticos de 
tradición castrense o militar, aplicados a partir de la destrucción y abandono de la ciudad a principios del siglo XVII, como medida de protección abaluartada del asentamiento. Su extensión alcanza 2,3 hectáreas, sin embargo, el plano no entrega información sobre el vecindario que creció en los exteriores de la fortificación.

Por último, el plano de Valdivia elaborado por Henrique Siemsen en 1853 (Figura 2c) muestra la fisonomía urbana de la ciudad tres décadas luego de la independencia de la corona española (1820) y comienzos de la colonización alemana en el sur de Chile. Esta pieza documental posee una escala gráfica en metros permitiendo mayor precisión en la conversión, relevando una escala de los terrenos ocupados efectivamente que ascienden a 112,6 hectáreas, sin considerar los humedales y áreas inundables interiores que habían comenzado ya a ser ocupados por las manzanas y predios particulares en el siglo XVIII.
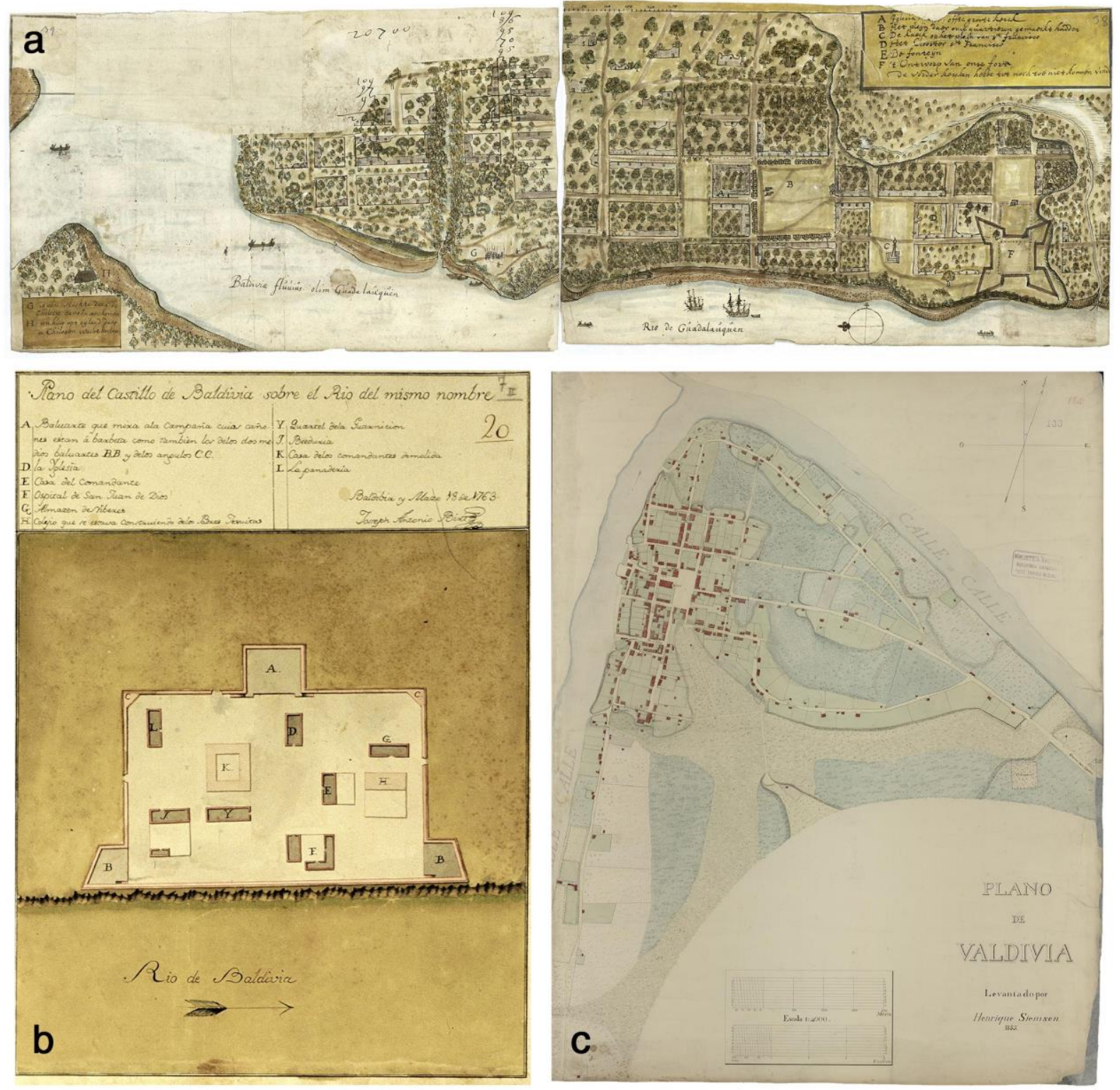

Figura 2. Cartografía histórica de la ciudad de Valdivia, 1643-1853.

2a) Plano holandés de la ciudad de Valdivia, 1643.

Fuente: Adán et al., 2017, Figura 5ạ, p. 5.

2b) La Plaza Real o castillo de Valdivia, Antonio Birt, 1763.

Fuente: Urbina et al., 2017, Imagen 8, p. 55.

2c) Plano de Valdivia. Henrique Siemsen, 1853.

Fuente: Urbina et al., 2017, Imagen 15, p. 59. 
El crecimiento urbano de la ciudad se ve reflejado en la existencia de nuevos caminos, al sur del torreón de Los Canelos y del convento San Francisco, que articulaban el centro de la ciudad con los sectores rurales y periféricos al sur, las Mulatas y Angachilla. A diferencia de los planos anteriores, el levantamiento de Siemsen tiene un mayor detalle en la trama urbana, considerando calles principales y segundarias, subdivisión predial y edificaciones en todo el conjunto. Otro elemento importante a resaltar en la cartografía es la posición topográfica de la calle Carlos Anwandter (12-14 msnm), ausente en la cartografía precedente, paralela al curso del río Callecalle.

La Figura 3 establece el crecimiento urbano de la ciudad de Valdivia en términos de la superficie representada en cada plano y las condiciones topográficas existentes, permitiendo establecer el límite exacto del área fundacional del núcleo urbano respecto de las etapas posteriores de crecimiento.

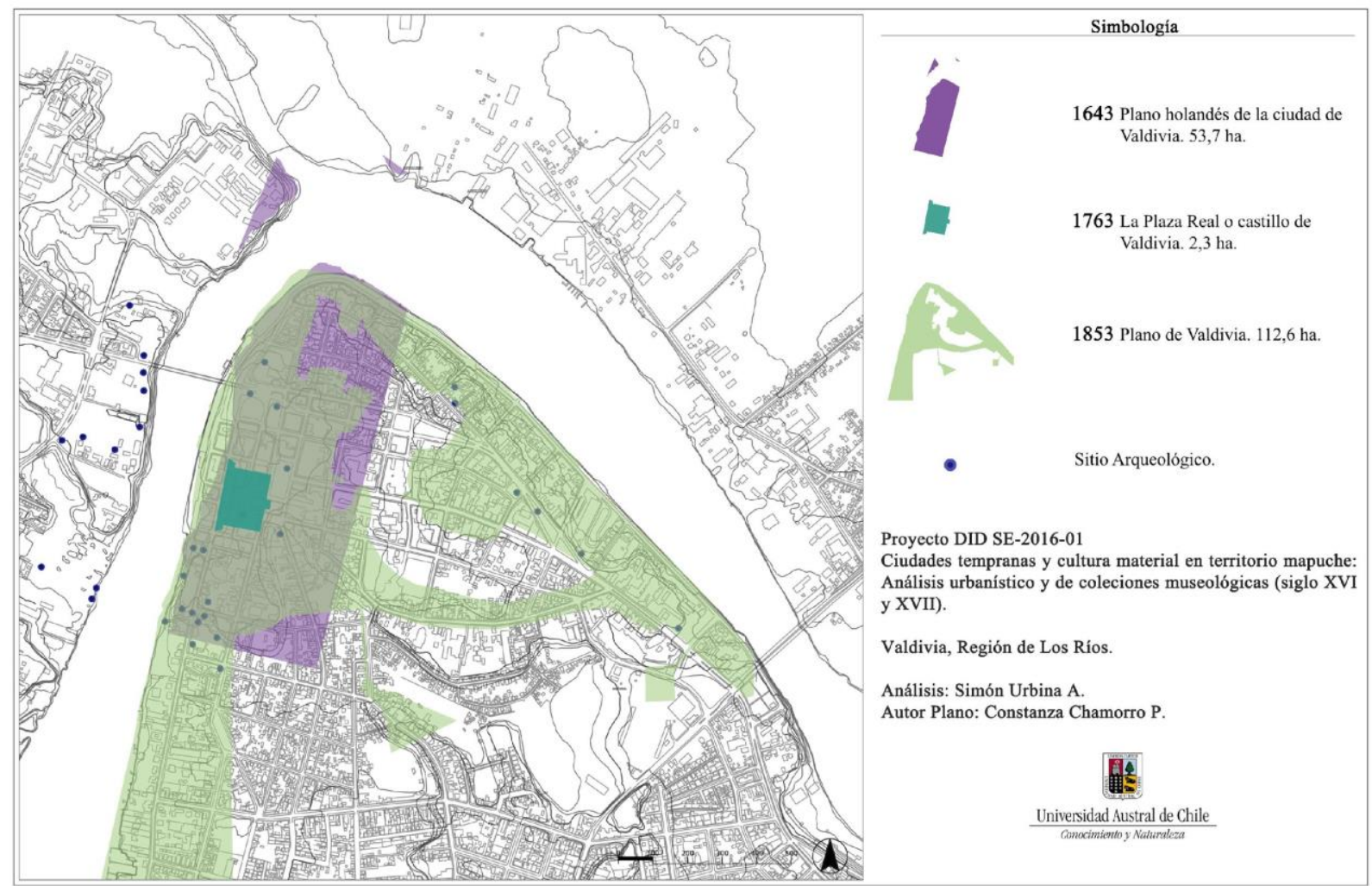

Figura 3. Crecimiento urbano de la ciudad de Valdivia (1643-1853)

Fuente: Elaboración propia sobre plano municipal 2006.

En el caso de la ciudad de Valdivia el crecimiento no es progresivo ascendente; existe un crecimiento estacionario que en momentos determinados es negativo, variando desde más de 50 hectáreas en el siglo XVI a menos de 3 al momento de la refundación en 1647, no obstante, entre mediados del siglo XVII y mediados del siglo XIX, el asentamiento experimentó un crecimiento por sobre las 100 hectáreas. La carencia de planos para el siglo XVIII y las primeras décadas del período Republicano no permiten mayores inferencias para este tiempo intermedio.

La subdivisión predial es posible visualizarla únicamente a partir del plano de 1853. Las numeraciones de las manzanas que hemos utilizado las hemos tomado del estudio de Gabriel Guarda (2009, p. 43). Como hemos establecido, la representación de lotes y deslindes internos de manzanas entregan significativa información sobre los procesos urbanos de la ciudad, especialmente en un momento de intensa transformación y asignación de sitios y tierras a los nuevos inmigrantes extranjeros.

Finalmente, la Figura 4 permite visualizar al menos 5 patrones de subdivisión predial, pudiendo existir otros que por espacio no analizamos con mayor detalle. Las manzanas tipificadas en los patrones 1 a 4 señalan un modelo colonial en su origen, mediante manzanas cuadrangulares o rectangulares divididas en solares, sin 
embargo, en todas ellas prima una división irregular posterior aplicada intensivamente o de modo progresivo generando predios de reducido tamaño. El patrón $n^{\circ} 5$ ejemplifica por su parte un formato de manzana adaptada a la topografía del terreno y aprovechamiento de terrenos colindantes con humedales interiores, relevando la relación de los espacios habitados con la topografía y características ecológicas del medio urbano.

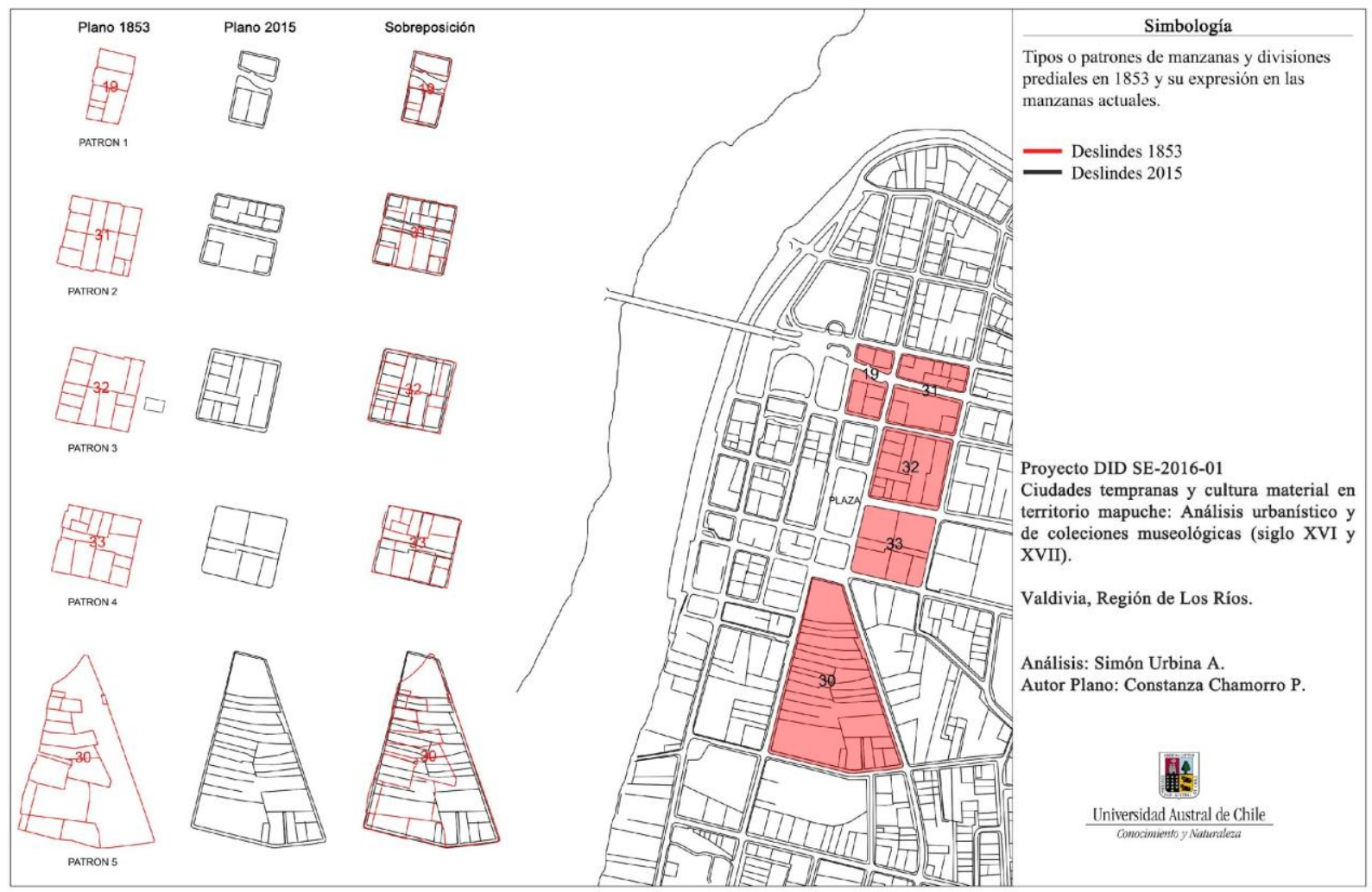

Figura 4. Subdivisión predial de la ciudad de Valdivia

Fuente: Elaboración propia sobre plano municipal 2006.

\section{Nueva Imperial}

En la Sala Medina de la Biblioteca Nacional de Chile, Santiago, se encuentra almacenado el plano del proyecto de la ciudad de Nueva Imperial de 1882 (Figura 5a). Esta pieza muestra la distribución del asentamiento diseñado con planta en damero, el mismo año en que se acuerda la compra de los terrenos al lonko Lemunao y su parcialidad (Navarro 2008, p. 348). El plano no lleva firma de los militares que ejecutaron el trazado o del ministro de guerra Carlos Castellón.
Si bien no se dispone de antecedentes arqueológicos referidos a una ocupación previa o datos documentales acrediten la existencia de familias habitando los terrenos donde luego se emplazará la ciudad, la venta de terrenos hace suponer que efectivamente en este lugar, junto al río Cholchol y en sus inmediaciones, existían asentamientos mapuches (ruka), como lo demuestran los registros fotográficos de la ciudad provistos por el ingeniero belga Gustave Verniory a fines del siglo XIX (ca. 1890-1895). 

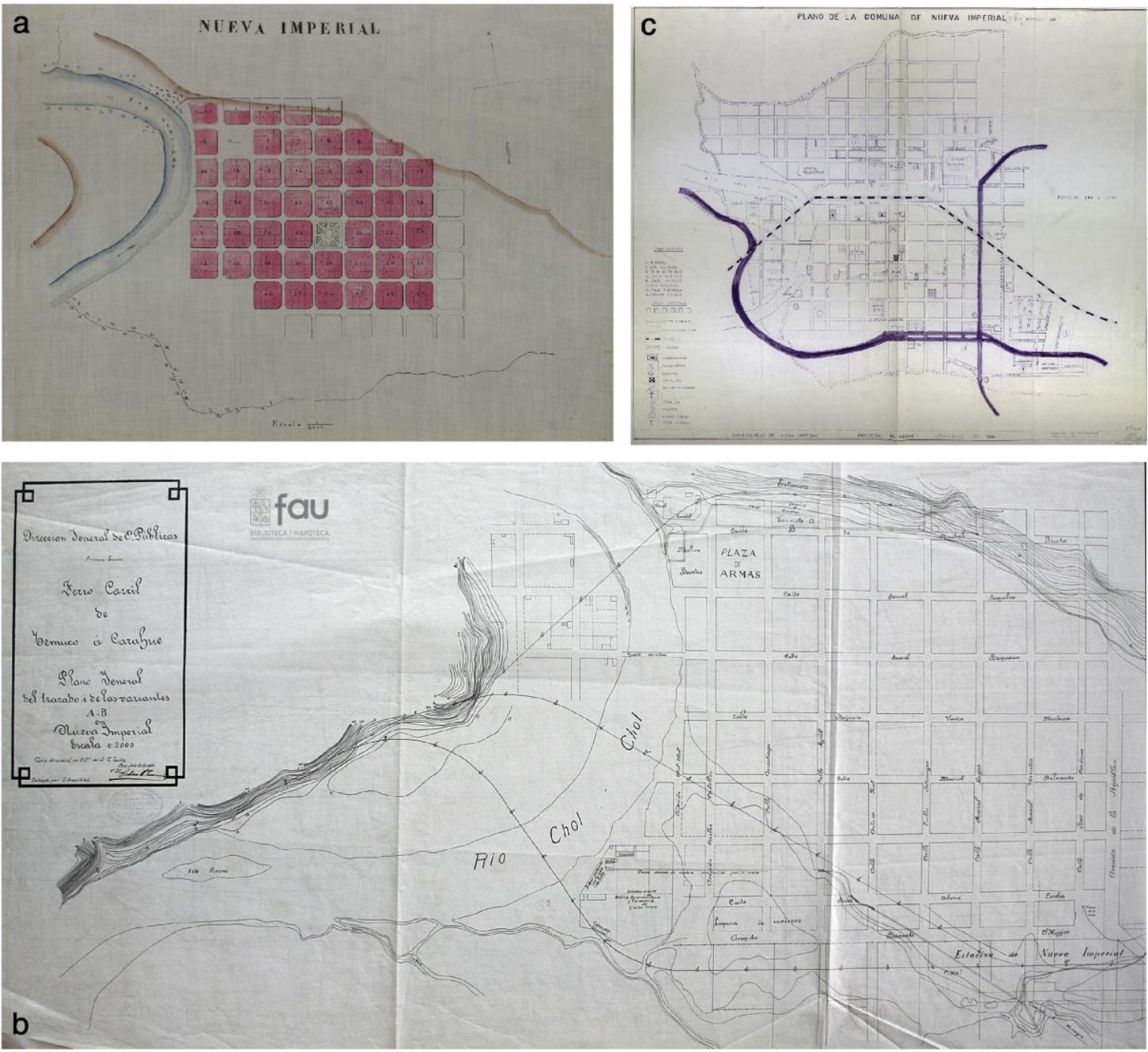

Figura 5. Cartografía histórica de la ciudad de Nueva Imperial, 1882-1910.

5a) Plano de la Nueva Imperial, 1882.

Fuente: Digitalización de los autores en Mapoteca Biblioteca Nacional de Chile.

5b) Ferro-Carril de Temuco a Carahue, 1910.

Fuente: http://biblio.uchile.cl/client/es_ES/search/asset/92294/0

5c) Plano de la comuna de Nueva Imperial, 1984.

Fuente: Digitalización de los autores en Mapoteca Biblioteca Nacional de Chile.

El detalle del plano de 1882 considera elementos importantes para la consolidación de la trama urbana, utiliza el damero de forma esquemática, extendiéndose al norte y oeste de forma idéntica con cuatro manzanas y en menor grado al oeste y sur, con tres y dos manzanas respectivamente, totalizando 47 unidades. También considera el programa de división predial de todas las manzanas diseñadas en solares y luego subdividiéndolas en mitades. Se agrega al diseño el uso de esquinas en ochavo o chaflán y en términos funcionales espacios públicos consolidados como plazas centrales y secundarias, edificios de funciones especiales, iglesia y cuarteles; por último, se demarcan elementos del paisaje como ríos y cursos de agua menores.

El segundo plano analizado corresponde a 1910 y se encuentra en la mapoteca de la Facultad de Arquitectura y Urbanismo de la Universidad de Chile en Santiago. Se trata, según la cédula del archivo que lo custodia, de una copia o calco del original cuya ubicación se desconoce. El plano corresponde a la Dirección General de Obras Públicas. 
El documento muestra el trazado hipotético de distintas líneas para el ferrocarril, habiéndose concretado luego sólo el trazado norte representado en el plano. Debido a lo anterior la topografía es un elemento destacado en este documento mediante curvas de nivel permitiendo reconocer el relieve y cuerpos de agua como riberas fluviales, esteros e incluso se representan pequeñas lagunas estacionales o humedales. Otro elemento urbanístico destacable es la omisión de la plaza de armas del plano de 1882 , nombre que recibe la plaza secundaria ubicada al noroeste. Todo indica que este espacio público se proyectaba de mayor importancia por su cercanía con el tendido de la línea férrea, su respectiva estación y el molino ubicado a orilla de río.

Finalmente analizamos el plano municipal de 1984, ubicado en la Mapoteca de la Biblioteca Nacional de Chile en Santiago. Este plano identifica las principales avenidas y un desarrollo de la infraestructura vial, considerando la línea férrea un componente primordial dentro de la traza urbana. La plaza de armas al centro vuelve a tener protagonismo y consolida los principales servicios en su entorno, la iglesia, escuelas, centrales telefónicas y banco. Paralelamente a los levantamientos planimétricos existentes, la ciudad se prepara para un eventual crecimiento y considera los lomajes del sector norte con proyecciones de crecimiento habitacional para nuevos habitantes.

La serie de planos entre 1882, 1910 y 1984, en conjunto con la planimetría actual de la ciudad es sumamente significativa puesto que permiten un análisis de la evolución urbana de Nueva Imperial desde el momento mismo de su fundación, considerando el inicio y término del siglo $X X$, y el comienzo del siglo XXI. En estos términos, la Figura 6 establece el crecimiento urbano de la ciudad, agregando información sobre la superficie y topografía del terreno sobre el cual la ciudad se dispone, el vínculo con el entorno próximo y los elementos paisajísticos predominantes. El análisis permite determinar el limite exacto del área fundacional de un núcleo urbano respecto de las etapas posteriores de crecimiento.

La transcripción lineal del plano de 1882 permite, del mismo modo, conocer la configuración interna de los lotes y deslindes de cada manzana; algunas de ellas enumeradas de noroeste a sureste, considerando al igual que en las ciudades coloniales el espacio dispuesto para la iglesia en los dos solares que enfrentan por el norte a la plaza de Armas.

A diferencia de la cartografía de 1910 y 1984, que no entregan información relevante sobre los lotes y deslindes internos de las manzanas, el plano municipal del año 2015 contiene toda la información actualizada y permite visualizar patrones de subdivisión predial existente luego de 130 años de desarrollo urbano, elemento que complementan la información sobre la extensión del área fundacional (> 80 hectáreas) y la vigencia del diseño en damero a fines del siglo XIX. Por último, en términos porcentuales, el área fundacional ocupa un $21,2 \%$ de la superficie actual de Nueva Imperial, similar proporción $(20,6 \%)$ si se considera el número de manzanas de 1882 versus la actual.

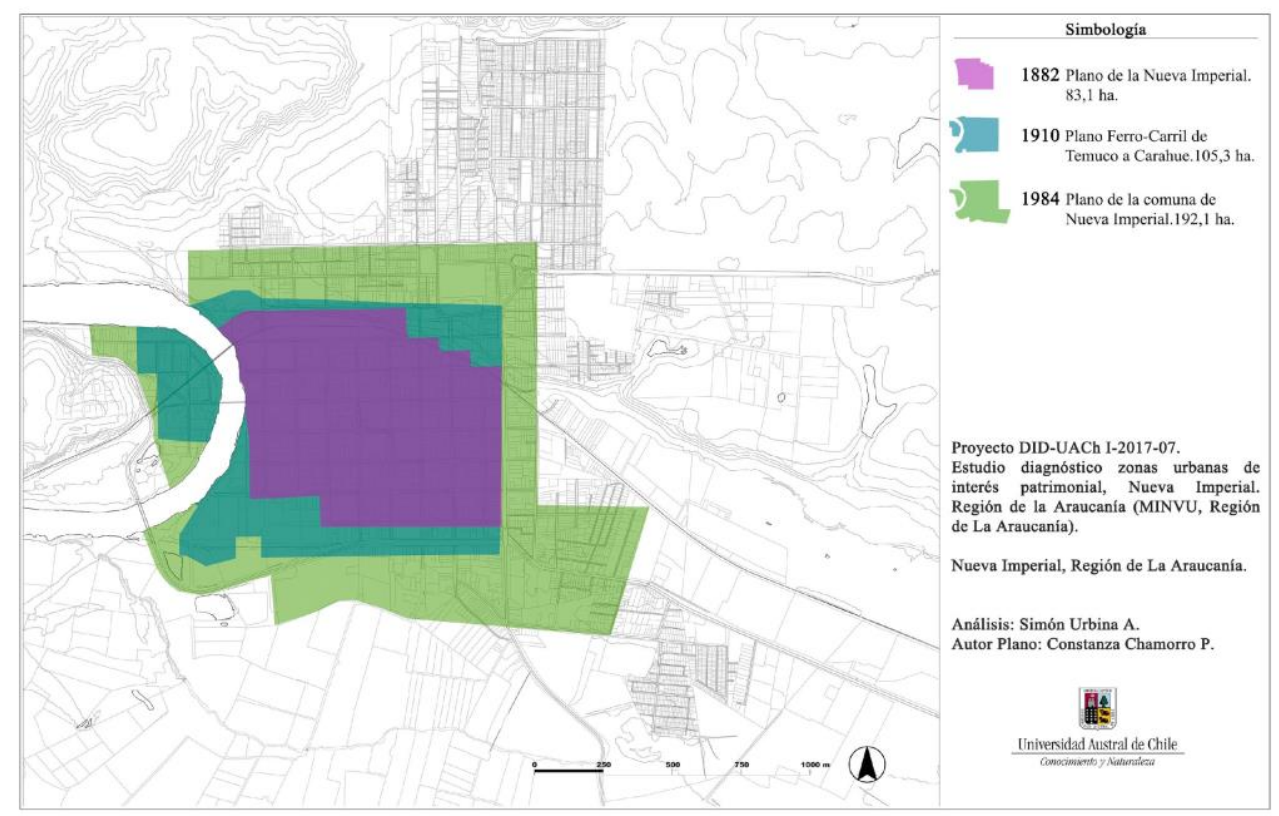

Figura 6. Crecimiento urbano de la ciudad de Nueva Imperial (1882-1984).

Fuente: Elaboración propia sobre plano municipal, 2015. 
Finalmente, hemos determinado la existencia de al menos 6 patrones o tipos de subdivisión predial de las manzanas (Figura 7). En términos generales la traza original de 1882 se mantiene parcialmente en la planta actual. Estas divisiones varían entre 4 y hasta 8 lotes por manzana y siguen patrones de orientación ortogonales respecto a la orientación general de las calles. La excesiva subdivisión predial actual corresponde a los cambios programáticos que ha tenido la ciudad $\mathrm{y}$ al régimen económico imperante, no obstante, la división original se conserva en la mayoría de las manzanas, especialmente en torno a los espacios públicos originales.

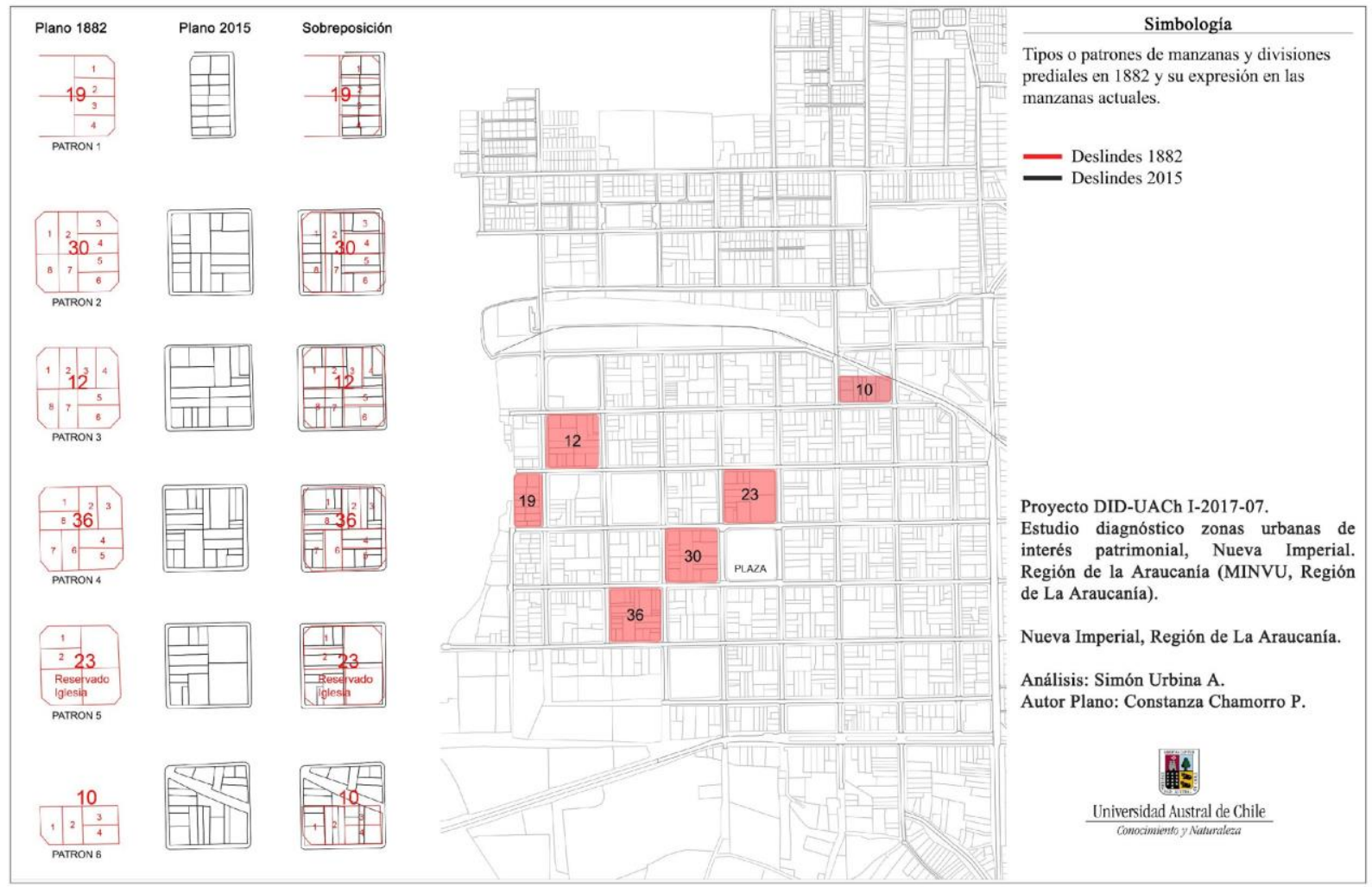

Figura 7. Subdivisión predial de la ciudad de Nueva Imperial

Fuente: Elaboración propia sobre plano municipal 2015 


\section{Discusión y conclusiones}

Las ciudades del sur de Chile fueron fundadas en territorios previamente habitados, razón por lo cual su constitución y mantenimiento dependió de procesos de negociación política a lo largo del período Colonial y Republicano y no sólo de la voluntad fundadora hispana y luego chilena. La trayectoria de crecimiento urbano de Valdivia estuvo determinada por las tensiones generadas en la fundación y refundación de la ciudad en un nodo geopolítico densamente habitado por población indígena (Urbina y Chamorro, 2016).

El damero como modelo de construcción y organización de Valdivia en el siglo XVI presenta particularidades que influyeron en su etapa urbana posterior reanudada en el año 1647 . De acuerdo con las tesis sobre la pervivencia en el siglo XIX del damero regular establecida por Guarda (1978) y el planteamiento de Borsdorf (2003) sobre la relevancia de este tipo de fundaciones para el posterior desarrollo de las ciudades chilenas, nuestra impresión es que la trama urbana de Nueva Imperial en 1882 permite inferir la mantención del damero como elemento fundante en las ciudades chilenas durante el período Colonial Tardío y el primer siglo del período Republicano, pero donde el elemento novedoso siguiendo la interpretación de Chueca (2011) - es la rigurosa subdivisión predial interna de las manzanas explicado por un nuevo contexto económico capitalista donde se tiende a maximizar el valor de la propiedad en núcleos urbanos nacientes en el siglo XIX y comienzos del siglo XX.

En ambas ciudades, luego del análisis por sobreposición de los planos históricos sobre la planta actual, se deduce una desigual impronta del trazado original, la configuración interna y forma de las manzanas fundacionales, especialmente en los alrededores de las plazas mayores o de armas.

En el caso de Valdivia, la sobreposición arroja como resultado un conjunto reducido de manzanas céntricas o aledañas a la Plaza de La República que corresponden a testigos remanentes del período Colonial, modificados con posterioridad a la colonización alemana (Guarda, 1994; Saelzer y Urbina, 2015), pero donde ahora puede visualizarse -siguiendo los resultados del análisis de Nueva Imperial-, que Valdivia también expresa una intensa subdisvisión predial de las irregulares manzanas o solares coloniales bajo un intento de aumentar su valor por metro cuadrado. Esto explicaría el acelerado proceso de división predial que muestra el plano de 1853 , aunque menos estandarizado que el de Nueva Imperial, resultando en la generación de diversos formatos en los lotes, los cuales se acomodan a la topografía y los cuerpos de agua interiores existentes (esteros y humedales) y cuyas consecuencias en la distribución de las viviendas pueden evaluarse hasta la actualidad (Hidalgo, Rodríguez y Alvarado, 2018).

El análisis de la subdivisión predial señala casos divergentes en ambas ciudades, con un patrón programado y gradual en el caso de Nueva Imperial -las manzanas se dividen entre 4 y 8 lotes- (Tabla 1), los cuales se repite en la mayoría de los casos; mientras que en Valdivia el patrón de subdivisión corresponde a algunas manzanas divididas en mitades y solares (cuartos) regulares y luego subdivididas de modo progresivo sin un esquema estandarizado.

Tabla 1. Comparación manzanas analizadas en Valdivia y Nueva Imperial

\begin{tabular}{|c|c|c|c|c|c|}
\hline Ciudad & $\mathrm{N}^{\circ}$ manzana & Superficie $\left(\mathrm{m}^{2}\right)$ & $\mathrm{N}^{\circ}$ predios (lotes) & Promedio $\left(\mathrm{m}^{2}\right)$ & $\begin{array}{l}\text { Oscilación tamaño } \\
\text { predios }\left(\mathrm{m}^{2}\right)\end{array}$ \\
\hline \multirow{5}{*}{$\begin{array}{l}\text { Valdivia } \\
\text { (1853) }\end{array}$} & 19 & 6.341 & 6 & 1.057 & $280-1.682$ \\
\hline & 30 & 39.019 & 16 & 2.439 & $89-17.876$ \\
\hline & 31 & 11.695 & 12 & 975 & $240-1.665$ \\
\hline & 32 & 13.677 & 11 & 1.243 & $570-3.244$ \\
\hline & 33 & 13.220 & 12 & 1.102 & $404-2.552$ \\
\hline \multirow{6}{*}{$\begin{array}{l}\text { Nueva } \\
\text { Imperial } \\
(1882)\end{array}$} & 10 & 4.513 & 4 & 1.128 & $1.043-1.241$ \\
\hline & 12 & 9.845 & 8 & 1.231 & $1.120-1.410$ \\
\hline & 19 & 9.224 & 6 & 1.537 & $1.128-2.203$ \\
\hline & 23 & 9.349 & 5 & 1.870 & $1.358-2.388$ \\
\hline & 30 & 9.909 & 8 & 1.239 & $1.133-1.436$ \\
\hline & 36 & 10.317 & 8 & 1.290 & $1.079-1.518$ \\
\hline
\end{tabular}

Fuente: Elaboración propia. 
Considerando los planos del siglo XIX como antecedentes directos de la situación actual, la Tabla 1 sistematiza las diferencias de escala, número de subdivisiones (predios o lotes) y la oscilación en el tamaño de los predios resultantes en ambas ciudades. Las acentuadas diferencias de tamaño entre las manzanas, la cantidad y variaciones en el tamaño de los predios o lotes en el caso de Valdivia confirman una evolución prolongada de la trama urbana por más de cuatro siglos y un complejo proceso de constitución y fragmentación de la propiedad urbana a partir del año 1647, donde podemos apreciar un cambio de régimen político (independencia del imperio español) y también económico que tensiona y transforma en pocas décadas la configuración urbana del siglo XVIII. Esta situación contrasta con la estandarización y aplicación de módulos repetitivos de división de las manzanas proyectadas y edificadas en Nueva Imperial, permitiendo, al amparo de una situación política más estable, un crecimiento progresivo posterior y una menor fragmentación de la propiedad.

Los indicadores señalan en el caso de Valdivia que manzanas regulares ubicadas en torno a la plaza de La República alcanzaban a mediados del siglo XIX entre 11 y 13 hectáreas de superficie y los predios dentro de ellas, dimensiones en un rango de 950 a $1.200 \mathrm{~m}^{2}$, aunque la oscilación real de los predios va desde los 89 a $3.244 \mathrm{~m}^{2} \mathrm{e}$ incluso en algunos predios sobre taludes cercanos zonas inundables superan los $17.000 \mathrm{~m}^{2}$. En Nueva Imperial, el diseño de 1882 muestra que las manzanas fueron regularmente trazadas con superficies entre 0,5 y 1 hectárea de terreno y subdivididas regularmente hasta en 8 predios o lotes. La superficie promedio de los lotes y la oscilación de sus tamaños mínimos y máximos confirman esta estandarización de los rangos de tamaño entre 1.000 y $2.400 \mathrm{~m}^{2}$.

\section{Comentarios finales}

El análisis comparativo de dos ciudades del sur de Chile por medio de información documental, planimétrica e histórica, entrega antecedentes importantes al momento de establecer las lógicas de asentamiento iniciales, la extensión de las áreas fundacionales y evaluar los elementos de diseño y planeamiento urbano hacia el futuro. Por otra parte, la conformación de series cartográficas para Valdivia y Nueva Imperial, con sus particularidades, enseñan al potencial histórico retrospectivo y proyectivo de los levantamientos planimétricos y los planos de proyecto que pudieran permitir aplicar esta metodología de análisis a un conjunto mayor de núcleos urbanos (Figura 1), así como facilitar el diseño de prospecciones e intervenciones arqueológicas en el subsuelo para verificar los resultados del análisis planimétrico.

En estos términos, el plano de 1643 muestra la segunda fase urbana de la ciudad de Valdivia donde sobre los elementos propios del damero inicial (1552-1575) han sido aplicadas reformas sustantivas al trazado, resultantes de nuevas disposiciones legales contenidas en las Ordenanza de Pobladores dictadas por Felipe II en 1573 (Nicolini, 1992-1993, p. 20-21, Fig. 8, p. 25; Guarda, 1986). Con todo, la transformación radical del espacio central de Valdivia, obligada por la nueva legislación que aprovecha la destrucción generada por el gran terremoto de 1575, significó la apertura de un nuevo eje de circulación central en sentido norte-sur, atravesando la Plaza Mayor (hoy calle Pérez Rosales), generando manzanas rectangulares y dos accesos adicionales a los ocho dispuestos en pares en cada esquina al espacio público principal.

La modificación de la retícula inicial de Valdivia, hipotéticamente constituida por manzanas cuadrangulares en torno a la Plaza Mayor, ideal gestado en América desde fines del siglo XV (Guarda, 1994; Palm, 1951), generó una modalidad mixta de tejido urbano que puede apreciarse siglos más tarde en el plano de Siemsen de 1853 y especialmente en la subsistencia de manzanas testigos como la $n^{\circ} 33$ (Figura 4) y un conjunto de manzanas rectangulares que prevalecen hasta el día de hoy. Precisamente el plano de Siemsen (1853) muestra en retrospectiva la fisonomía que Valdivia desarrolló a partir de 1647 y hasta mediados del siglo XIX, habiéndose refundado Valdivia sobre las ruinas del damero de fines del siglo XVI.

El plano de Siemsen posee el valor retrospectivo pues representa con detalle el crecimiento urbano en los exteriores de la plaza murada (1647-1798), desmantelada a fines del siglo XVIII, y para la cual no se dispone de planos precisos más que los que dibujan el interior de la fortificación. Esta condición de plano-testigo es la que ha permitido a diversos autores dibujar y situar la ubicación de esta fortificación en la planta urbana de Valdivia (Urbina et al., 2017, p. 55; Urbina y Chamorro, 2016, p. 510; Guarda, 2009).

El crecimiento que se observa en el vecindario -casa, huertas y manzanas-, fuera de los límites de la Plaza Real, sería el resultado de las Ordenanzas políticas y Económicas de la Plaza de Valdivia dictadas en 1741 por Manso de Velasco y el Reglamento para la guarnición de la Plaza de Valdivia de 1753, con lo cual se autorizaba a los gobernadores a otorgar repartimiento y mercedes de sitio dentro y fuera del recinto de la plaza y fomentar el trabajo productivo en estas tierras (Donoso y Velasco, 1928; Guarda, 1978; RChHyG, 1928, pp. 377-378). En el plano se Siemsen, son ejemplo de ello, la extensa manzana $n^{\circ} 30$ 
(Figura 4) y los predios que se adosan a las calles Las Mercedes (hoy Carlos Anwandter), Picarte, Beauchef y Los Canelos (hoy General Lagos) donde predomina un patrón rural o de caserío junto a una calle o camino principal.

De esta manera, durante la segunda mitad del siglo XVIII y primera mitad del siglo XIX el proceso urbano extramuros de la plaza de Valdivia se consolida combinando un trazado de calles y manzanas que, adaptados al antiguo damero de manzanas cuadradas y rectangulares, genera formatos irregulares de ocupación acomodados el terreno que pudiéramos asimilar a una modalidad de urbanismo topográfico (Saelzer, 2014). Adán et al. (2017) plantean que la intervención de la topografía y sistema de humedales y cursos interiores de agua han sido documentados, mediante el desagüe o desecación humedales ya en el siglo XVIII e intensificados en el siglo XIX para ampliar la superficie edificable de Valdivia.

En el caso de la ciudad de Nueva Imperial, el plano de diseño o proyecto de 1882 demuestran una vez más la vigencia del damero hispano colonial en pleno período Republicano. Como enseña el caso de Valdivia, la continuidad de este patrón de diseño durante la etapa borbónica del imperio español había adquirido nueva vigencia a partir de las fundaciones impulsadas por la Junta de Poblaciones y Manso de Velasco a partir de 1740; probablemente, como enuncia Guarda (1978), por la ausencia de técnicos se replicaron los diseños de planta del siglo XVI, sin influencia alguna de la impronta renacentista posterior que generara nuevos diseños urbanos, distintos al damero, durante el período de reformas borbónicas (1700-1808).

El análisis del plano de fundación de Nueva Imperial y de los levantamientos planimétricos del siglo XX enseñan, sin embargo, la aplicación de un elemento novedoso, el uso de esquinas en ochavo o chaflán. En el caso de Nueva Imperial, las esquinas ochavadas fueron aplicadas a la totalidad del diseño de la ciudad y sus efectos pueden percibirse en la actualidad en toda el área fundacional, con los accesos principales de viviendas ubicadas en las líneas oblicuas que unen los costados de las manzanas subsistentes. Aunque desconocemos el vínculo entre el anónimo autor del plano de 1882 y los urbanistas ibéricos que los inspiraron, sin duda la influencia que se prevé entre ellos debiera dar cabida a nuevas investigaciones en la materia, específicamente esclarecer la formación de los militares o civiles que intervinieron en las distintas experiencias de planeamiento urbano en la ocupación chilena de la Araucanía.

Con todo, la evidencia analizada nos permite señalar que el urbanismo desarrollado en el marco de la expansión militar y territorial meridional de la República de Chile (post 1820), siguió el modelo colonial hispanoamericano. Sin embargo, este fenómeno no es extensible a todos los casos (p.e. Pitrufquén), si bien recobró su vigencia, especialmente al sur del río Biobío, como lo demuestra el caso de Nueva Imperial y otras ciudades fundadas entre 1827 y 1904, las cuales valdría la pena analizar en el futuro (ver Figura 1). Cabría preguntarse por las razones de esta solución de continuidad o redescubrimiento funcional del modelo urbano ortogonal en las nuevas ciudades chilenas del siglo $\mathrm{XIX}$, como por su estrecha vinculación con la constitución de la propiedad privada y la mayor rentabilidad del suelo en la nueva economía capitalista.

Si bien la estandarización de los atributos generales del modelo urbano heredado de la colonización hispana de América, el damero, habría sido mantenida en sus rasgos generales por parte de las autoridades civiles y militares chilenas, ocupando territorios indígenas meridionales incorporados forzosamente a la república, fue el aumento exponencial de la subdivisión de la tierra y del valor monetario de los terrenos o lotes urbanos los que inciden mayormente en la transformación urbana en el siglo XIX. Esta faceta del proceso histórico plantearía que el diseño ortogonal de las ciudades chilenas de esta nueva época independiente y expansiva, fue conservada como un instrumento de ocupación colonial, pero sobre todo de capitalización de los nuevos terrenos urbanos.

Agradecimientos: Este trabajo es resultado de los proyectos FONDECYT 1171735 y DID SE-2016-01 de la Universidad Austral de Chile. El análisis de Nueva Imperial ha sido efectuado originalmente en el proyecto "Estudio diagnóstico zonas de interés patrimonial, Nueva Imperial, La Araucanía" (MINVU, La Araucanía). A Leonor Adán, Virginia Vázquez, Juan Carlos Olivares, Andrés Horn, Ricardo Mendoza y las y los colegas de la Dirección Museológica de la Universidad Austral de Chile, por su apoyo, colaboración y aportes a este trabajo. En la llustre Municipalidad de Valdivia al arquitecto Manuel Quillán. A los evaluadores de este trabajo, por sus aportes fundamentales y observaciones que han permitido mejorar la primera versión del manuscrito [R] 


\section{Referencias}

Adán, L., S. Urbina y M. Alvarado (2017). Asentamientos humanos en torno a los humedales de la ciudad de Valdivia en tiempos prehispánicos e históricos coloniales. Chungará Revista de Antropología Chilena, 49(3), 359-377. http://dx.doi.org/10.4067/S0717$\underline{73562017005000020}$

Barría, T. (2017). El paisaje de Valdivia y las trazas de ocupación en los mapas holandeses de 1643. En A. Vega (Comp.), Del mapa al mundo: objetos, escalas $e$ imaginarios territoriales, pp. 393-402. Santiago: Memorias 60 Simposio iberoamericano de historia de la cartografía.

Benavides, A. (1988). La arquitectura en el virreinato del Perú y en la Capitanía General de Chile. Santiago: Editorial Andrés Bello.

Bermann, M. (1993). Continuity and Change in the Household Life at Lukurmata. En M. Aldenderfer (Ed.) Domestic Architecture, Ethnicity, and Complementarity in the South-Central Andes, pp. 114-135. Iowa: University of lowa Press.

Borsdorf, A. (2003). Cómo modelar el desarrollo y la dinámica de la ciudad latinoamericana. EURE, 29(86), 37-49. http://dx.doi.org/10.4067/S025071612003008600002

Calvo, L. M. (2008). La cartografía histórica como fuente para la historia urbana colonial. En R. Gutierrez (Ed.), Espacios de encuentro cultural. Arquitectura y urbanismo en Iberoamérica, pp. 44-60. Morelia: Universidad Michoacana de San Nicolás de Hidalgo.

Chueca, F. (2011). Breve Historia del Urbanismo. Madrid: Alianza Editorial.

Contreras, A. (2015). Transformación territorial de Puerto Montt del intersticio hostil al escenario metropolitano (Tesis de Magister en Arquitectura y Diseño). Pontificia Universidad Católica de Valparaíso, Valparaíso.

Donoso, R. y Velasco, F. (1928). Historia de la constitución de la propiedad austral. Santiago de Chile: Imprenta Cervantes.

Espinoza, D. y Zumelzu, A. (2016). Valdivia y su evolución post-terremoto 1960: enfoques, factores escalares y condicionantes. Urbano, 33, 14-29. Recuperado de http://revistas.ubiobio.cl/index.php/RU/article/view/ $\underline{2303}$

Guarda, G. (1965). Santo Tomás de Aquino y las fuentes del urbanismo indiano. Boletín de la Academia Chilena de Historia, 72, 5-50. Recuperado de http://www.cielonaranja.com/gabrielguardaurbanismo.pdf
Guarda, G. (1978). Historia Urbana del Reino de Chile. Santiago: Editorial Andrés Bello.

Guarda, G. (1986). En torno a las Plazas Mayores. En Academia Chilena de la Historia (Ed.) Fundación de ciudades en el Reino de Chile (pp. 115-131). Santiago: Academia Chilena de la Historia.

Guarda, G. (1994). Una ciudad chilena del siglo XVI. Valdivia 1552-1604: Urbanística, Res pública, Economía, Sociedad. Santiago: Ediciones Universidad Católica de Chile.

Guarda, G. (2009). Cuatro Siglos de evolución Urbana. Valdivia 1552-1910. Valdivia: Facultad de Arquitectura y Urbanismo, Universidad Austral de Chile.

Hidalgo, R., Rodríguez, L., y Alvarado, V. (2018). Arriba del cerro o sobre el humedal: producción de naturaleza y expansión inmobiliaria en ciudades marinas y fluviales. El caso de Valparaíso y Valdivia, Chile. Diálogo Andino, 56, 87-100. https://dx.doi.org/10.4067/S071926812018000200087

Munita, D., Peña-Cortés, F. y Farías, A. (2013). Arqueología y planificación territorial en Chile, situación actual y perspectivas. El caso de estudio de la provincia de cautín, región de la Araucanía. Chungará Revista de Antropología Chilena, 45(2), 293-310. http://dx.doi.org/10.4067/S0717-

73562013000200006 Navarro, L. (2008). Crónica militar de la conquista y pacificación de la Araucanía. Santiago de Chile: Pehuén Editores.

Nicolini, A. (1992-1993). La traza de la ciudad hispanoamericana en el siglo XVI. Anales del Instituto de Arte Americano e Investigaciones Estéticas Mario J. Buschiazzo, 29, 15-35.

Ordenanzas políticas y económicas de la Plaza de Valdivia (1928). Revista Chilena de Historia y Geografía (RChHyG), LVI (60), 376- 393. Recuperado de http://www.memoriachilena.cl/archivos2/pdfs/MC00 67814.pdf

Ortiz, O. (1971). Arqueología de los poblados hispánicos de la Patagonia Austral. Segunda etapa de excavaciones en Rey Don Felipe y nuevos antecedentes sobre Nombre de Jesús. Anales del Instituto de la Patagonia, 2, 3-19. Recuperado de http://www.bibliotecadigital.umag.cl/bitstream/hand le/20.500.11893/214/Ortiz_Anales vol2_1971_p.419.pdf? sequence $=1$ \&isAllowed $=y$

Palm, E. (1951). Los orígenes del urbanismo imperial en América. Ciudad de México: Instituto Panamericano de Geografía e Historia, Comisión de Historia. 
Saelzer, G. (2014). Urbanismo topográfico según la cartografía histórica: desde las fortificaciones hasta las plazas de Valparaíso. Revista AUS, 15, 3439. https://doi.org/10.4206/aus.2014.n15-07

Saelzer, G. y Urbina, S. (2015). Urbanismo fluvial en el apogeo industrial de Valdivia: desaparición y recuperación (ca. 1850-2012). Revista de Urbanismo, 33, 97-123. $\quad$ http://dx.doi.org/10.5354/0717$\underline{5051.2015 .34285}$

Romero, A. y Ajata, R. (2014). Zonas arqueológicas y gestión del territorio en la ciudad de Arica (Chile). Diálogo Andino, 44, 57-74. http://dx.doi.org/10.4067/S071926812014000200006

Rosas, J., Hidalgo, G., Strabucchi, W. y Bannen, P. (2015). El Plano Oficial de Urbanización de la Comuna de Santiago de 1939: Trazas comunes entre la ciudad moderna y la ciudad preexistente. $A R Q$, 91, 8293. https://dx.doi.org/10.4067/S071769962015000300013

Sanhueza, J., Henríquez, M., Prado, C., Reyes, V. y Núñez, P. (2004). Presentación y comentario al simposio Estado Actual de la Arqueología Histórica en Chile: Teoría y Métodos. Chungará Revista de Antropología Chilena, 36(1), 161-174.

http://dx.doi.org/10.4067/S0717$\underline{73562004000300013}$
Urbina, S., Adán, L., Munita, D. y Mera, R. (2012). Arquitectura arqueológica y sitios patrimoniales sin arquitectura en el perímetro urbano de Valdivia: cartografía descriptiva actualizada y comentarios sobre su valor científico integral. Revista AUS, 12, 4-9. https://doi.org/10.4206/aus.2012.n12-02

Urbina, S., Adán, L. y Chamorro, C. (2017). Carta arqueológica del área fundacional de Valdivia: arquitectura, materiales constructivos y tradiciones cerámicas. Revista AUS, 21, 51-60. Recuperado de http://revistas.uach.cl/index.php/aus/article/downlo ad/528/542

Urbina, S. y Chamorro, C. (2016). Cartografía histórica comparada de los castillos de Valdivia, el estuario (bahía de Corral) y el río Cruces, siglos XVII-XVIII. En F. Mena (Ed.), Arqueología de Patagonia: de Mar a Mar (pp. 505-514). Coyhaique: Ediciones CIEP/ Ñire Negro Ediciones.

Zumelzu, A., Burgos, R. y Navarro, S. (2016). Expansión periférica y procesos de centralidad en Valdivia entre 1900-2015: un análisis desde la perspectiva de la sintaxis del espacio. Revista AUS, 19, 24-30. https://doi.org/10.4206/aus.2016.n19-05 